\title{
O mal-estar dos civilizadores: ou como os agricultores lembram a floresta em Engenheiro Beltrão, Paraná*
}

\author{
Ely Bergo de Carvalho**
}

A construção de memórias está interligada aos projetos das pessoas e grupos sociais (Velho, 1988). Os agricultores aqui estudados - em um total de 37 relatos orais de vida, que podem ser descritos, na média, como agricultores familiares, tecnificados, cultivando basicamente soja e milho -, estão inseridos em um projeto de uma agricultura tecnificada de commodities, com altos usos de insumos, apesar de alguns estarem sendo, claramente, expulsos do mercado por não terem conseguido "ser competitivos". É a partir desse projeto especifico que lembram da grande floresta que havia na região, e se relacionam com os poucos, pequenos e degradados remanescentes florestais que ainda hoje existem. Isso implica que outras memórias podem ter sido construídas por outros grupos e que não foram abordadas nesta pesquisa.

O objetivo deste artigo é entender como eles constroem suas memórias sobre o processo de desflorestamento da região, a partir da colonização dirigida, ocorrida no atual município de Engenheiro Beltrão, noroeste do Paraná, Brasil, a partir de 1947. Talvez possamos situar dois

* O presente texto é parte de minha dissertação de mestrado, defendida em 2004, orientada pela professora Dra . Eunice Sueli Nodari, no Programa de Pós-Gradução em História da Universidade Federal de Santa Catarina, sob o título: Sombras do passado, projetos de futuro: as florestas nas memórias dos agricultores de Engenheiro Beltrão - Paraná, 1947-2003 e financiada pelo CNPq.

** Doutorando do Programa de Pós-Graduação em História da Universidade Federal de Santa Catarina. UFSC. 
grandes processos de transformação da paisagem do município: entre 1947 e 1970, temos um processo de desflorestamento, da área até então coberta predominantemente por uma floresta estacional semidecidual povoada por indígenas e caboclos. Um pequeno capítulo da expansão da fronteira agrícola brasileira no século XX, no caso incentivado, principalmente, pela implantação de lavouras cafeeiras a partir de modelo agrícola "de enxada" e com predominância de pequenas e médias propriedades, chegando a população rural a 21.853 habitantes; nas décadas de 1970 e 1980, ocorre um processo brutal de modernização da agricultura, o café vai entrar em declínio e as culturas principais vão passar a ser: soja, milho, cana-de-açúcar e trigo, ao mesmo tempo em que há um expressivo êxodo rural, a população rural diminuiu para 6.293 habitantes, e a urbana sobe de 3.386 para 8.378 habitantes. Continua a predominar a agricultura familiar, mas graças ao modelo de tecnificação o tamanho de cada propriedade familiar fica cada vez maior, ao mesmo tempo em que a região se consolida como uma das mais desflorestadas do Brasil. A partir da década de 1990, continua a haver uma tendência a concentração da terra e aumento do êxodo rural, em 2000 a população rural havia diminuído para 2.945 habitantes.

Ao mesmo tempo em que, nestas últimas décadas, se desenvolveu na sociedade brasileira um processo de "ecologização", um aumento da preocupação pública com os problemas ambientais. E não apenas se tornou um tema debatido na sociedade civil como se tornou um valor positivado e hegemônico. Lívia Barbosa, em um artigo em que busca mapear a penetração, a importância e o significado da problemática ambiental no seio da sociedade brasileira, afirma que pelo menos a partir do início da década de 1990: “O meio ambiente se tornou o grande referencial para todos os grupos. Do ponto de vista político, a adaptação ao tema ecológico, ainda que de forma superficial, apresenta-se como a única saída competitiva" (Barbosa, 1991, p. 242). A autora constata isso a partir da forma como, até mesmo os garimpeiros, após muito tempo se contrapondo frontalmente aos ecologistas, passaram, no final da década de 1980, a atuar "sob a ideologia do verde" ainda que de forma superficial. Afinal, hoje, mesmo empresas produtoras de biocidas afirmam categoricamente em sua propaganda institucional que são "empresas que respeitam a natureza", como tive oportunidade de acompanhar juntamente com um grupo de agricultores. Portanto, "ecologização", aqui, não implica 
a adoção de um modo de vida que leve a um "desenvolvimento sustentável", mas apenas esta mudança de postura na qual a "natureza" deixa de ser percebido, em geral, como uma fonte inesgotável de recurso, para ser reconhecida como um "problema" que inspira cuidados, o que dá uma conotação positiva, em geral, para o que se identifica como "ecologicamente correto". Isso nos leva ao segundo objetivo deste trabalho, a saber, entender melhor em que termos estes agricultores aderem à "ideologia do verde".

Iniciemos pelo papel do agricultor no processo de colonização dirigida: o agricultor é um civilizador. Quando perguntado a um entrevistado o que mudou no município desde a sua chegada, ele afirmou: "Mudo, [...] foi vindo, foi melhorando... até, se vê a coisa ficou boa, [...] o pessoal foi derrubando aquelas mata e formando café, e já do café passou para a soja, para o trigo e está hoje esse movimento" (José n. 12). ${ }^{1}$ A forma como os agricultores se representam, com um certo orgulho, neste processo, é pelo "trabalho": "Nós cortávamos tudo no machado, dois homens tac...tac...tac.. tac.. tac.. e a bicha [árvore] caía emmm... bum... era uma coisa de se ver, foi muito trabalho, nós mesmos limpamos tudo" Luiz (n. 1 caderno de campo). O mesmo entrevistado quando lhe foi perguntado "Em que contribuiu para construir a cidade?" -, respondeu: "Sim porque trabalhamos muito para construir o Brasil no cabo da enxada" (Pochapski, 2002). Sua memória aqui ressoa o discurso oficial e junto com a recorrência do trabalho, como motivo de orgulho nas entrevistas, faz-me lembrar o quadro, O café, de Cândido Portinari, um ser humano com mãos e pés enormes, um ser humano que era só trabalho na construção da nação (Silva, 1998, p. 122-3).

O trabalho é civilizador, e o agricultor é “só trabalho". Não é possível, aqui, analisar as especificidades do grupo pesquisado no tocante ao discurso do trabalho. Somente quero chamar a atenção para a ligação entre civilização - trabalho - desflorestamento. É o desflorestamento que positiva a sua região em relação ao "sertão", no qual falta a civilização,

1 As primeiras entrevistas serão identificadas, nas citações, apenas por um número, de 01 a 30 , e por um nome fictício. $\mathrm{Na}$ época das entrevistas, optou-se por não identificar nominalmente os entrevistados, pois isto permitiria maior liberdade por parte deles. Já as outras entrevistas serão identificadas com o nome completo do entrevistado. (Os grifos são sempre meus) 
falta o "trabalho": "lá pela frente [...] na fronteira tem sertão... tem mato até hoje" (Luiz n. 1).

Mas há falas dissonantes a respeito da ação "civilizadora" sobre a floresta. Em certos momentos, alguns agricultores, quando narram, apresentam um mea culpa: "naquela época a gente praticava totalmente errado, não foi deixada a... a bera da água" (João n. 13). Ou, ainda, um posicionamento mais intrigante é expresso pelo entrevistado Alcides (n. 26), quando narra que há alguns anos tem em sociedade "um meio alqueire" de vargem (na beira de um curso d'água), que está coberto por vegetação nativa, tendo procurado saber como se poderia "derrubar aquele mato" para plantar arroz, e "aproveitar aquela terra nova", sendo que em substituição plantaria meio alqueire "em eucalipto ou santa barbara" (árvores exóticas), porém "não nos deixaram fazer... essas coisas" (n. 26). Afinal, apesar da legislação ambiental ter sido praticamente letra morta durante o processo de colonização dirigida, a partir da década de 1970 ela passou a ser, paulatinamente, cumprida. Esclareço que já o Código Florestal, de 1934, protegia a vegetação à beira dos cursos d'água e o Código Florestal atual, Lei Federal n. 4.771, de 15 de setembro de 1965, com várias modificações posteriores, protege a mata ciliar como parte da Área de Preservação Permanente, (APP), sendo vedado o corte da vegetação nativa ou qualquer outra forma de exploração. Ora, antes de iniciar essa entrevista, a esposa do senhor Alcides havia afirmado que "era importante manter uma reserva de mato na propriedade". O entrevistado concordou com a esposa e reafirmou que "era importante plantar árvores em torno dos corgos" (Alcides n. 26 - caderno de campo). Como entender uma fala aparentemente contraditória? Como entender um mesmo fato estar associado a elementos de orgulho e arrependimento?

Pode-se resumir a questão da seguinte forma: os agricultores, primeiro, no período da colonização dirigida, foram louvados como agentes da civilização e, agora, o que antes era louvado é condenado como ato bárbaro pela moral hegemônica. Tal mudança está em consonância com o discurso dos jornais locais sobre este tema, que, na segunda metade da década de 1970, passam, também, por tal alteração: do louvor da ação civilizadora do desflorestamento à condenação do desflorestamento como algo errado (Carvalho, 2005).

Desta forma, os agricultores, em alguns casos, vão procurar justificar suas ações ou de seus pais: "eles não tinha como morar debaixo de 
uma árvore e derrubar o resto da mata então eles começaram a derrubada por ali [na margem do córrego] embora ache que nessa época também nem a Companhia informou... nem nada" (Arnaldo n. 15). Outros, explicitamente, se posicionam afirmando que o fato de não terem deixado reserva florestal foi "errado": "foi assim um erro grave na época, que derrubamos a mata 100\%" (Fabio n. 16).

Não se solicitou diretamente a opinião dos entrevistados em nenhum caso, a pergunta utilizada sempre foi "por quê?". Outros agricultores não se justificaram, ativeram-se a constatar que: "nós desmatamos, derrubamos, e plantamos hortelã" (Lucas n. 28), ou deram uma justificativa ligada à necessidade econômica. O que deve ser destacado é que não houve vozes contrárias à "preservação da mata" e o que se escolhe para falar e silenciar também é importante (Pereira, 1991), pois tal ausência revela o que não se considera correto afirmar publicamente. Com certeza, há posições entre os agricultores contrárias a "deixar tanto mato" mas não contrárias a "preservar a natureza" - que apareceriam melhor, talvez, em situações distintas da entrevista formal. De qualquer forma, isso permite entender os elementos de orgulho e arrependimento na fala dos agricultores, mas não a fala do agricultor Alcides.

Para elucidá-la vou apresentar a trajetória de vida de alguns entrevistados, a fim de mostrar que há um enorme esforço para se criar uma certa coerência na trajetória de vida, com os valores hegemônicos atuais e com os projetos de futuro, dos agricultores.

Um exemplo disso pode ser percebido na fala do entrevistado Antônio (n. 24), sendo que para melhor compreendê-la cabe chamar a atenção para sua trajetória de vida. O entrevistado mora na zona rural, no distrito de Sertãozinho, no imóvel que pertenceu a seu pai, tendo nascido em 1932, no município de Campo Mourão, Paraná. A origem de sua família é paulista, seu avó veio para "Campo de Mourão", provavelmente, no início do século passado. A família é "pioneira” na região, o pai viveu ali quase uma vida, e o entrevistado, a infância e adolescência. Época em que a região era predominantemente "mato", época em que, em geral, a caça era uma forma de buscar alimentação básica, como afirma o citado entrevistado: na "casa [...] do meu avô não faltava caça, não faltava carne". Em 1935, o pai do entrevistado mudou para a área conhecida como Sertãozinho, atual Engenheiro Beltrão, para ocupar as terras que seu avô havia "requerido", junto ao governo do estado. Eles criavam porcos e 
produziam cana-de-açúcar e café, levando tais produtos em lombo de mula para Guarapuava. Com o processo de colonização dirigida, na região, eles plantaram mais café e depois outro "impulso ocorreu com o hortelã”. Foi em 1956 que ele adquiriu as primeiras terras, 41,1 hectares. Hoje, ele possui 229,9 hectares e dedica-se ao cultivo de café, de soja e à produção de leite. Quando questionado se deixou "reserva" de mata na propriedade, ele respondeu:

Nas outras áreas em que fui, eu que abri, onde eu tinha minha propriedade, ficou e continua até hoje. Tenho mina, tem palmito, aqui na frente tem figueira, peroba, ainda pra mostrar, moita de mato que nós não derrubamos, não quer dizer que foi o tanto suficiente, mas a beira de água eu nunca mexi, eu não mexo. Eu sou muito favorável à mata [...]. Eu deixei porque eu acho que a água tem que ser limpa e a mina d'água tem que ter cobertura. [...] É a maneira que eu penso, eu falei com diversos companheiros que a autoridade tem que estar de acordo que o próprio cidadão ajude a manter o meio ambiente, mas numa boa, sem lei... quer dizer, não adianta nada você chegar no cidadão e impor tanta lei e multa; de noite pega fogo numa mata, você sabe... sabe lá quem colocou fogo.... quem pode provar? Então eu acho que não tem nada melhor que nós trabalharmos com amizade, com consideração, um com os outros. Não estou avançando em nada no que é dos outros... Eu dou muito valor na mata, eu gosto disso, aí... foi onde eu me criei eu gosto de mais disso, se eu comprar uma propriedade amanhã de mato eu não derrubo... eu nunca cacei... eu nunca matei um bicho assim... [...] você veja bem, eu me criei no meio do mato e nunca cacei e nunca... nunca apoiei ninguém caçar... nunca dei um tiro num bicho... eu vou viver disso... vou matar bichinhos? Não. [...] Toda a vida foi desse jeito... [...] Que nem nós temos o rio da Varge, o rio Claro que a gente vê uma água poluída [...] Isso aqui acho que é um crime, hoje, pra gente que viu o tanto de peixe que dava o rio da Varge, hoje o que se vê a... água que tem hoje é um crime, eu sou revoltado com isso aí, eu não gosto disso aí.

Essa longa citação é extremamente esclarecedora, tal fala voltada para demonstrar uma "preocupação com a natureza" - bem como os 
silêncios dos agricultores que responderam de forma objetiva e seca, não fazendo defesa de posições pró-ambientalistas, mas também se abstendo de expressar posições anti-ambientalistas - são, em parte, geradas pela situação de entrevista, pois a própria temática já deixa alguns entrevistados ressabiados. Entretanto, tamanha preocupação de aparentar estar em sintonia com o que, hoje, é considerado ecologicamente correto revela como Lívia Barbosa estava certa em afirmar que há uma "adaptação do tema ecológico" por parte dos mais diferentes grupos sociais, mesmo que de forma "superficial" (Barbosa, 1991, p. 242). Todavia, tal "adaptação" se deu nos próprios termos dos agricultores. É evidente a existência de uma contradição entre o padrão de agricultura por eles adotado e a preservação de remanescentes florestais (Carvalho, 2002), mas isto não explica a contradição entre achar "importante preservar a floresta" e a situação de risco em que se encontram os remanescentes florestais, afinal, mesmo aqueles agricultores em condições econômicas de ao menos cumprir a legislação, em geral, não o fazem. A grande questão é entender que ao anunciar a importância de "preservar a floresta" os agricultores estão pensando coisas bem diferentes do que, em geral, o movimento ambientalista o faz.

Entender por que é importante "preservar a floresta" e em que termos isto se coloca para os agricultores permite fugir de uma lógica dicotômica, que ora os coloca como criminosos ambientais, ora como heróis salvadores do bucólico mundo rural e, assim, compreender suas ações dentro das contradições nas quais estão inseridos.

Por exemplo, um agricultor como José Antonio Casado Paschoal, proprietário da área de 186,3 hectares, sendo 104,06 de floresta, a qual permitiu sua transformação em Unidade de Conservação, como Reserva Particular do Patrimônio Natural, parece extraordinário, mas seu caso parece mais compreensível quando inserido em sua trajetória de vida.

Nascido no estado de São Paulo, em 1931, José A. C. Paschoal é de ascendência espanhola, seus pais fizeram a trajetória típica, dos migrantes vindos de São Paulo para o norte do Paraná. Seus pais, inicialmente, vieram trabalhar nas fazendas de café paulistas, como colonos, até que conseguiram comprar 12,1 hectares em Lençóis Paulista. Em 1947, seu pai comprou 96,8 hectares "de mato", em Marialva, no Norte Novo do Paraná. Foi para lá com a família, e "abriram um pedaço de mato e fizeram um rancho de palmito”. Foi deixada uma reserva de mata na propriedade 
porque "achava bom também ter um pouco de mato", até depois foi deixada uma área maior onde a capoeira cresceu e eles deixaram para "não invadir o rio", até porque "tinha uma cachoeira". Quando ele casou seu pai falou: "ajudar vocês eu não posso, a única coisa que eu vou ajudar é que tem terra ai vocês derrubam mato e plantam, o que vocês puderem plantar vocês não pagam renda". Foi a partir daí que eles foram "trabalhando, esforçando mais do que podia", e conseguiram comprar 12,1 hectares. O café para ele "pouca coisa deu” foi com a criação de gado e a lavoura branca que conseguiu "aumentar mais" suas terras. Em 1992 sua esposa faleceu com câncer, então ele já tinha um patrimônio de 229,9 hectares, "resolveu distribuir" 169,4 hectares entre os seus quatro filhos, um homem e três mulheres, sendo que, salvo um dos genros todos os demais são agricultores. Vendeu então um sobrado que havia construído na cidade de Maringá - com a intenção de morar lá com a esposa e um dos filhos, mas não "deu tempo" disto se realizar em virtude do falecimento de sua esposa - e "juntou” mais algum dinheiro para comprar uma fazendinha.

Em 1993 o corretor o levou para ver uma fazendinha, mas ele não gostou, porque "[era] tudo terra limpa, e não tinha, tudo muito areia também, e não tinha benfeitoria". Depois, foi levado a umas terras, que segundo o corretor, era: "uma fazendinha que tem pouca terra para plantar, mas tem bastante mato, só que mato não pode derrubar". Pois, desde o início da década de 1990, o governo federal proibiu o corte dos remanescentes do bioma da Mata Atlântica. Mas, o entrevistado falou: "não tem problema, não faço questão, ai eu vim ver aqui, conforme eu cheguei aqui eu gostei", ele explica que gostou, porque "tinha bastante benfeitoria, tinha telefone, tinha sede da fazenda, tinha a piscina, quintal grande, frutas". Por isto ele falou para os corretores: "tá bom eu compro aqui, acho que dá para terminar meus dias aqui [risos]". Ele argumenta contra aqueles que lhe perguntam se não pode derrubar a mata: "pra que derrubar o mato, deixa o mato ai [...] tem os bichinhos, bastante passarinho... tem tatu, tem capivara, tem porco do mato, tem tucano, passarinhada tem à-vontade, bichinho, [...] nessa mata tem uma mina de água, que é água que nós bebemos, uma água sadia". E argumenta ainda: "uma peroba dessa ai, uma pessoa que nunca viu uma madeira vê e fica abismada com um pau daqueles, se a gente derrubar acaba com isto ai, nunca o cara vai ver mais, então por que vamos querer destruir, deixa ai’. Por isto, explica que concordou 
quando o "pessoal da prefeitura" o procurou para transformar a área em RPPN, falando que a prefeitura ira receber uma verba extra do governo do estado com isto, o ICMS-Ecológico. Ele concordou, e a RPPN. "Fazenda São João" foi, legalmente, criada em 1997, mas reclama que a prefeitura municipal não cuida das estradas para impedir a erosão e queimadas na capoeira que fica às margens da mata. O entrevistado, logo depois de mudar para Engenheiro Beltrão, "arranjou uma companheira” e ficou com ela oito anos, mas "não deu certo" e separaram. E, hoje, um genro, a filha e duas netas moram com ele, mas este seu genro vendeu os 36,3 hectares que recebeu de herança e comprou terra em Dourados, no Mato Grosso do Sul. Então, "por isso", ele está "fazendo planos de, se der certo, vender” em Engenheiro Beltrão e comprar no Mato Grosso do Sul, pois “eles querem que eu compre para lá também”. Para ele, isto depende de poder comprar uma área maior lá. Ele acredita que houve uma valorização em suas terras com floresta devido à maior pressão para cumprimento da legislação ambiental: "os vizinhos, [em Engenheiro Beltrão], ninguém queria comprar aqui, porque tinha muito mato", mas "hoje em dia o pessoal está precisando de reserva, né, e não vou vender isso para desmatar, mas pra reserva eu posso vender" (Paschoal, 2003).

O entrevistado está vislumbrando a possibilidade legal nova de se constituírem reservas legais coletivas, previstas na Lei Estadual n. 11.054, de 14 de janeiro de 1995, ou seja, a área com cobertura florestal obrigatória, de $20 \%$ do imóvel rural, prevista no Código Florestal Lei Federal n. 4.771, de 15 de setembro de 1965, que é praticamente inexistente, não necessariamente precisaria ser no imóvel, pode ser em uma outra área, na mesma região, na qual o agricultor seja também proprietário, individual ou na forma de condomínio. Isto facilita o cumprimento da legislação e, ao mesmo tempo, possibilita a criação de áreas maiores com cobertura florestal, o que é melhor para a manutenção da biodiversidade. O fato de o entrevistado estar pensando em negociar a sua área de mata como Reserva Legal mostra como se forma, ou pode se formar, um mercado de "mercadorias ligadas à preservação ambiental".

Quando era questionado sobre a reserva de mata que havia na propriedade de seu pai, em São Paulo, ele tece o seguinte comentário: "voltei [a São Paulo, muitos anos depois] porque me deu saudade de ver meu lugar onde eu nasci, né, eu voltei lá, ai ficamos triste de ver que o córrego tinha acabado, tinha assoreado tudo, ai já as minas estavam cobertas. 
Aí mudou tudo... eles tinham arrancado as casas, a benfeitoria que tinha, eles tinham acabado com tudo, tava só a invernada lá” (Paschoal, 2003).

A tristeza gerada no entrevistado, ao ver a paisagem das terras em que nasceu, agora tão degradada, não está vinculada à destruição da "mãe natureza" e, sim, ao desenraizamento (Worster, 2003) que sente quando pensa no córrego, nas árvores, no terreirão e no pomar, que eram os suportes de suas lembranças. Também, o entrevistado Antônio nos revela o quanto uma árvore pode ser um suporte de lembranças ao narrar ter plantado uma carreira de eucaliptos, nas margens da rodovia que passa ao lado de seu sítio, afirmando que plantou "há uns 50 anos", quando ele era "moleque". Sobre o motivo de ter plantado eucaliptos, ele responde:

Quando nós plantamos [...] meu pai achou bonito plantar uma carreira... era para ser de fora a fora, mas como morreu umas mudas [...] então a gente achava bonito plantar aquelas árvores, né, por isto foi plantado, e não foi mexido... hoje inclusive eu... não é pelo valor do eucalipto mais pela recordação do meu pai, eu queria manter essa moita de eucalipto, estou vendo que vão tirar tudo [o Departamento de Estradas de Rodagem - D.E.R.] e não tenho direito a nada. (Antônio n. 24).

Isto mostra o quanto a velocidade das transformações na paisagem destrói os lugares de memória do grupo estudado. Daí pode-se entender porque o entrevistado José A. C. Paschoal buscou uma fazenda para comprar em que houvesse benfeitorias. Não estava buscando apenas um lugar confortável para morar, buscava "um lugar para terminar os seus dias", um lugar que fosse o "seu lugar", que lhe fosse familiar, mesmo que não tivesse nascido ali, ou seja, não é simplesmente um suporte para memória individual, sim para memória social, se não do grupo, pelo menos, de uma geração.

O espaço é um meio de transmissão da memória, a disposição dos elementos fixa a recordação, como na metáfora do palácio da memória agostiniana (Burke, 1992, p. 241). Em especial para "camponeses", para os quais há uma

[...] importância constantemente recorrente da geografia local como estrutura de memorização: montes, grutas, casas de lavoura 
e campos todos têm as suas memórias para os camponeses de falarem delas. Este padrão reflete com toda a evidência as estruturas das rotinas quotidianas ao ar livre; mas o espaço geográfico da comunidade é por sua vez socializado segundo esta mesma via, conferindo-lhe as suas associações passadas um significado que faz sentido para os seus habitantes, em contraposição às geografias mais anônimas que o rodeiam: espaço e tempo firmam-se na construção da identidade comunitária. (Fentress \& Wickham, 1992, p. 141).

As transformações radicais na paisagem geradas pelo processo de modernização agrícola, reconfiguraram as estruturas de sociabilidade local, muitos agricultores passaram a morar na cidade e, na zona rural, os vizinhos ficaram mais longe uns dos outros, ainda há locais de convergência da vida comunitária, como campos de futebol e a capela, mas estes não são mais tão exclusivos quanto antes, na cidade, em especial os agricultores mais ricos, têm outros lugares e outras preferências de sociabilidade como os clubes recreativos e clubes de serviço. A rápida transformação na paisagem ajuda no trabalho de esquecer a época da agricultura da "enxada", em que era tudo "tudo braçal", "tudo café", como também, ajuda a esquecer o que havia antes, inclusive a floresta.

Mas quando se anda com qualquer pessoa com mais de quarenta anos e que tenha vivido ali, como muitas vezes andei, pela zona rural do Município, a cada curva que se faz com o carro, pode-se ouvir: aqui ficava a casa de fulano, ali ficava a casa de sicrano e lá a casa de beltrano, algumas vezes seguido de uma longa digressão sobre o que aconteceu com a família de "beltrano e sicrano"; ali ficava o "campo de futebol onde jogávamos"; aqui era a "mata das pombinhas, chamávamos assim porque era bom de caçar". Lugares de memória, destruídos e semidestruídos, fragmentos remanescentes da antiga paisagem, por meio dos quais a memória projeta no espaço aquilo que não mais existe.

Nas trajetórias de vidas até aqui descritas as relações com a floresta às vezes são ambíguas, a floresta é mercadoria mas, também, é bem mais que mercadoria. A relação do ser humano com o meio é bem mais que um processo contínuo de mercantilização do ambiente (Carvalho, 2005). E é em tais relações, por vezes contraditórias, que a sobrevivência dos remanescentes florestais, talvez, possa ser negociada. Uma vez que, hoje, 
é notória a insuficiência dos mecanismos de comando e controle, imposto unilateralmente pelo Estado (Bacha, 1998), como lembra o entrevistado Antônio (n. 24), "de noite pega fogo numa mata, [...] quem pode provar?" Considerando, ainda, o processo de concentração fundiária que passa a região (Carvalho, 2002), cabe cada vez mais buscar alternativas de conservação florestal que incluam os agricultores, buscando construir com eles novos projetos de desenvolvimento, mas para tal cabe compreender a forma especifica como cada grupo social compreende o "problema ambiental". O segundo objetivo desta pesquisa visa contribuir com isto, pois estas trajetórias de vida, também, permitem buscar responder à questão, anteriormente, colocada: em que termos eles estão pensando a preservação da floresta? Há, pelo menos, quatro elementos da relação entre agricultor e floresta que devem ser ressaltados, como resposta a questão citada:

1) Em primeiro lugar, a questão do apreço pela "natureza desnaturalizada", ordenada e racionalizada (Pereira, 1999, p. 11-47), ou seja, "bonito" é a "carreira" de eucaliptos, homogêneos e não a "floresta/sertão", "caótica". Como bem expressa o comentário do Sr. "Leonardo":

Onde é pedreira que não dá para mecanizar, e fazer de enxada dá prejuízo, então nós plantamos uma moita de eucalipto [...] 50 metros assim... então desmatamos aquilo lá, cortamos aquele colonhão, carpimos, e plantamos eucalipto, dá uma moita bonita, né. (Leonardo, n. 20).

Há uma grande valorização em manter-se "limpa" a terra. E, não necessariamente, isso visa um aumento de produção, algo utilitarista. Eu, por exemplo, lembro da "mata" que ficava em torno de uma nascente no sítio do meu avô em Engenheiro Beltrão. Não se cultivava nada, mas ele fazia absoluta questão de manter a área, sob as árvores, "limpa" e gastava muitas horas de serviço em tal atividade. Manter um terreno "limpo" era reafirmar que naquela área se trabalhava, reforçando-se a auto-imagem de trabalhador; reforçava-se, ainda, a propriedade/posse da terra, como se verá. Mas é, também, um exemplo de como o grupo pesquisado tem dificuldade de considerar "belo e aprazível" o "mato", bonito mesmo é terra "bem cuidada". As árvores isoladas, o pomar, a silvicultura, o campo cultivado, são bonitos, já “mato” é, por definição, o antônimo disto, é “terra inculta". 
2) Em segundo lugar, apesar de alguns agricultores fornecerem argumentos "preservacionistas" para manter a "mata" na propriedade, por exemplo, ao afirmar a importância da mata ciliar para conservação dos cursos d'água e evitar a erosão, outros valorizam a preservação das matas por motivos que desvinculam a sobrevivência da mata de sua própria sobrevivência. Assim, "preservar a natureza" é não "matar passarinhos": "aqui no meu sítio eu não deixo matar nenhuma pombinha, se aparecer morta não é aqui que mataram" (Osvaldo n. 22) ou, ainda, um outro agricultor, ao explicar porque foi "errado" ter cortado a mata nas margens do rio, afirma: "é a beira do rio era bom para os bichos, essas coisas, né, é passarinho" (Leonardo n. 20). Tal desvinculação, também, se expressa ao considerarem os remanescentes florestais como espécies de "relíquia museológica", como bem exemplificado na fala de J. A. C. Paschoal: "vê e fica abismada com um pau daqueles, se a gente derruba [...], nunca o cara vai ver mais" (2003).

3) A floresta e as árvores podem ser lugares de memória (Nora, 1993). Como espero ter esclarecido, com os comentáriose a trajetória de vida de José A. C. Paschoal. Em alguns casos, as árvores podem ser as raízes, através das quais, alguns tentam se segurar do desenraizamento permanente do mundo moderno.

4) E, em quarto lugar, os agricultores, em geral, não concebem, tal como o movimento ambientalista normalmente o faz, que preservar seja manter intocado, não utilizar (Barbosa, 1991, p. 237). O que transparece na dificuldade de um entrevistado entender por que "eles não querem que entrem certas frutas" nas áreas de mata ciliar, como "laranjeiras" (Josep n. 3), ou seja, plantas exóticas e "úteis". Da mesma forma transparece, na afirmação do entrevistado Miguel Glaba, que: a área de mata ciliar que "teve" que plantar em sua propriedade agora é "do governo". Informação logo corrigida por seu filho, que explica que a área é deles, mas não podem "mexer" (Glaba et. al., 2003). Não se trata aqui apenas da dificuldade de pensar que uma propriedade privada tem uma função social, o entendimento é outro: se não posso trabalhar, nem explorar a área, logo ela não é minha, raciocínio que talvez esteja mais de acordo com a tradição de pensamentos e de valores do grupo estudado.

Segundo Eric Hobsbawm, "para os camponeses, a posse sem trabalho é impensável, uma vez que toda a terra que tenham deve ser utilizada". Para além do discurso moderno do trabalho, isto seria parte dos 
"pressupostos sociais, políticos e do pensamento estratégico subjacente" aos camponeses ocidentais (Hobsbawm, 1998, p. 241-244). Uma outra fonte para a legitimidade moral da idéia, segundo a qual é necessário o trabalho para legitimar a posse/propriedade da terra, é sugerida por José de Souza Martins, ao afirmar que:

Uma característica importante da frente de expansão em todo o país, para datá-la historicamente, é que quando se deslocavam juntos ricos e pobres deslocavam-se com base nos direitos assegurados pelo regime sesmarial. Embora o regime de sesmarias tenha cessado às vésperas da Independência e só tenha sido substituído por um novo regime fundiário com a Lei de Terras de 1850, ele continuou norteando as concepções de direito à terra de ricos e pobres e, em muitos casos, norteia até agora. A concepção de que épreciso ocupar a terra com trabalho (na derrubada da mata e no seu cultivo) antes de obter reconbecimento de direito, era próprio do regime sesmarial. Do mesmo modo, a concepção de que o trabalho gera direito de propriedade sobre os frutos do trabalho também era próprio desse regime fundiário. Nele, o domínio estava separado da posse. O domínio era da Coroa. Quando, por acaso, o sesmeiro deixasse de cultivar a terra ou de obter dela frutos para pagar tributos, a terra se tornava devoluta (ou realenga, como então se dizia, isto é pertencente ao rei). Podia por isso ser novamente distribuída pelo representante da Coroa, bastando que alguém a ocupasse e, depois, a requeresse, como ocorreu freqüentemente. Do mesmo modo, a casa de um agregado construída em terras de sesmaria ou data de outrem, bem como suas roças e cultivos, não sendo ele escravo, lhe pertenciam legalmente, sendo a relação com o sesmeiro apenas relação de enfiteuse. Portanto, o trabalho de fato gerava direito sobre bens produzidos e sobre a terra beneficiada ou, melhor, sobre o benefício incorporado à terra, como era o caso do desmatamento. (Martins, 1996, p. 43-4. Grifo meu).

Martins, ao argumentar sobre estas persistências do "imaginário monárquico", na frente de expansão, afirma que isto não se deve apenas a "arcaísmos religiosos", "mas também a uma concepção de direito muito próximo dos pobres: a dos direitos (de uso) gerados pelo trabalho em 
oposição aos direitos (de propriedade) gerados pelo dinheiro" (Martins, 1996, p. 44). Não cabe, entretanto, aqui, debater sobre a gênese desta idéia e sim, o que interessa aqui, é constatar a sua persistência.

Não se quer afirmar que os agricultores estudados vivem dentro de uma ordem moral tradicional, ou seja, de uma campesinidade, pelo contrário, os agricultores em pauta, na atualidade, têm uma mínima campesinidade (Woortmann, 1987). Mas, apenas, apontar a persistência de alguns valores que continuam presentes em novas configurações, isto, acredito, nos permite entender como tal grupo tem dificuldade em conceber que uma determinada área de terra não possa ser usada.

Com tais ponderações e levando em consideração as dificuldades econômicas stricto senso (Carvalho, 2002), pode-se entender que apesar dos agricultores, na atualidade, serem "muito favoráveis à mata", a pouca mata que resta na região ainda corre perigo, sendo motivo de vigilância por parte do Estado, e de ações judiciais por parte do Ministério Público e de ONGs ambientalistas. Assim, a afirmação do entrevistado Alcides, (que narra a sua trajetória de desflorestador e ao mesmo tempo afirma a importância de "preservar a mata"), não deve ser entendida nem como uma mentira para agradar o entrevistador, nem pode ser, plenamente, compreendida a partir, apenas, das dificuldades econômicas do entrevistado para cumprir a legislação ambiental. E, sim, pode ser melhor compreendida a partir da percepção específica do grupo sobre o que é "preservar a natureza/florestas".

\section{Referências bibliográficas}

BACHA, Carlos José Caetano. Gestão florestal no Paraná. In: LOPES, Ignez Vidigal et. al. (org.). Gestão Ambiental no Brasil: experiência e sucesso. 2a ed. Rio de Janeiro: FGV, 1998, p. $155-182$.

BARBOSA, Lívia. Garimpo e meio ambiente: águas sagradas e águas profanas. Estudos Históricos, Rio de Janeiro, v. 4, n. 8, p. 229-243, 1991.

BURKE, Peter. A história como memória social. In: O mundo como teatro: Estudos de antropologia histórica. Lisboa: Difel, 1992, p. 234-51.

CARVALHO, Ely Bergo de. História e exploração de um recurso natural: as árvores no município de Engenheiro Beltrão-PR. Guairacá, Guarapuava, n. 18, p. 7-24, 2002.

Os historiadores e as florestas: dez anos depois de A Ferro e Fogo. Esboģos, Florianópolis, n. 13, 2005. (no prelo). 
FENTRESS, James; WICKHAM, Chris. Memória Social: Novas perspectivas sobre o passado. Lisboa: Teorema, 1992.

GLABA, Miguel; GLABA, Inglina F.; GLABA, Antônio. Miguel Glaba, Inglina F. Glaba, Antônio Glaba: depoimentos [26 abr. 2003]. Entrevistador: Ely Bergo de Carvalho. Araruna, 2003. 2 fitas cassete.

HOBSBAWM, Eric. Ocupações de terra por camponeses. In: Pessoas extraordinárias: resistência, rebelião e jazz. São Paulo: Paz e Terra, 1998. p. 241-276.

MARTINS, José de Souza. O tempo da fronteira: retorno à controvérsia sobre o tempo histórico da frente de expansão e da frente pioneira. Tempo Social, São Paulo, v. 8, n. 1, p. 25-70, maio, 1996.

NORA, Pierre. Entre memória e história: A problemática dos lugares. Projeto História, São Paulo, n. 10, p. 7-28, dez. 1993.

POCHAPSKI, Marcelo José. Relatório de Estágio supervisionado em turismo e meio ambiente. (Curso de Turismo e Meio Ambiente da Faculdade de Ciências e Letras de Campo Mourão). Campo Mourão, 2002.

PASCHOAL, J. A. C. José Antônio Casado Paschoal: depoimento [13 mar. 2003]. Entrevistador: Ely Bergo de Carvalho. Engenheiro Beltrão, 2003. 1 fita cassete e caderno de campo.

PEREIRA, Lígia Maria Leite. Relatos orais em ciências sociais: limites e potencial. Análise \& Conjuntura. Belo Horizonte, v. 6, n. 3, p. 109-127, set./dez. 1991.

PEREIRA, Magnus Roberto de Mello. De árvores e cidades ou a difícil aceitação do verde nas cidades de tradição portuguesa. In: SOLLER, Maria Angélica; MATOS, Maria Izilda S. (org.). A cidade em debate. São Paulo: Olho d’Água, 1999.

SILVA, Francisco Carlos Teixeira da. Vargas e a Questão Agrária: A construção do fordismo possível. Diálogos, Maringá, v. 2, n. 2, p. 113-127, 1998.

WOORTMANN, Klaas. "Com parente não se negoceia": O campesinato como ordem moral. Anuário Antropológico. p. 11-73, 1987.

WORSTER, Donald. Transformações da terra: para uma perspectiva agroecológica na história. Ambiente e Sociedade [online]. 2003, v. 5, n. 2, p. 23-44. Disponível na World Wide Web: $<$ http://www.scielo.br/scielo.php?script+sci_arttext\&pid=S1414-753X200300002000003 \&Ing=pt\&nrm=isso > . Acesso em 26 jul. 2004.

VELHO, Gilberto. Memória, Identidade e Projeto. Tempo Brasileiro, Rio de Janeiro, n. 95, p. 119-126, 1988.

Resumo: O objetivo deste trabalho é compreender o processo de construção social de memórias sobre a floresta entre agricultores, e como este grupo social adere ao processo de "ecologização" ocorrido nas últimas décadas na sociedade brasileira e mundial. O recorte espacial se limita ao município de Engenheiro Beltrão-Paraná, do momento de inicio da colonização dirigida com a fundação da empresa colonizadora em 1947 até 2003, quando foram realizadas as últimas entrevistas. 
Palavras-chave: memória social; ecologização; lugares de memória; desflorestamento; agricultores.

The Non-Welfare of the Settlers: or How the Farmers Remember the Forest in Engenheiro Beltrão, Paraná

Abstract: The aim of this study is to comprehend the process of the social construction of memories about the forest among the farmers, and how this social group fits the process of "ecologization" which took place in the last decades both in the national and internetional societies. A special focus is limited to a town called Engenheiro Beltrão-Paraná, Brazil, from the beginning of driven colonization with the founding of a colonizing interprise in 1947 until 2003, the time when the last interviews were done.

Keywords: social memory; ecologization; places of memory; deforestation; farmers. 

